\title{
The Impact of a Ten-Week Physical Exercise Program on Health-Related Quality of Life in Patients with Inflammatory Bowel Disease: A Prospective Randomized Controlled Trial
}

\author{
Peter Klare $^{a}$ Johanna Nigg ${ }^{a}$ Johannes Nold ${ }^{c}$ Bernhard Haller ${ }^{b}$ \\ Anne B. Krug a, d Sebastian Mair ${ }^{a}$ Christoph K. Thoeringer ${ }^{a}$ \\ Jeffrey W. Christle ${ }^{c}$ Roland M. Schmid ${ }^{a}$ Martin Halle ${ }^{c}$ Wolfgang Huber ${ }^{a}$ \\ all. Medizinische Klinik and ${ }^{b}$ Institut für Medizinische Statistik und Epidemiologie, Klinikum rechts der Isar, \\ Technischen Universität München, München, and ' Zentrum für Prävention und Sportmedizin, Klinikum rechts \\ der Isar, Technischen Universität München, München, ${ }^{d}$ Institut für Immunologie, Ludwig-Maximilians-Universität \\ München, München, Germany
}

\section{Key Words}

HRQOL · Physical exercise · IBD · Physical activity

\begin{abstract}
Background: Improving health-related quality of life is a primary target of therapy for patients with inflammatory bowel disease. Physical activity has been demonstrated to improve health-related quality of life in several patient populations with chronic disease. There are very few studies investigating the effects of physical activity on health-related quality of life in inflammatory bowel disease. The primary purpose of this study is to investigate the effects of 10 weeks of moderate physical activity on health-related quality of life in patients with inflammatory bowel disease. Methods: Thirty patients with mild to moderate IBD (Crohn's Disease Activity Index (CDAl) $<220$ or Rachmilewitz Index $(\mathrm{RI})<11$ ) were randomized 1:1 to either supervised moderate-intensity running thrice a week for 10 weeks or a control group who were not prescribed any exercise. Health-related quality of life, symptoms, and inflammation were assessed at baseline and after 10 weeks. Results: Participants were 41 \pm 14 years $(73 \%$ female), had a body mass index of $22.8 \pm 4.1$
\end{abstract}

(c) 2015 S. Karger AG, Basel

$0012-2823 / 15 / 0913-0239 \$ 39.50 / 0$ $\mathrm{kg} / \mathrm{m}^{2}$, and an average CDAl or RI of $66.8 \pm 42.4$ and $3.6 \pm$ 3.1. No adverse events occurred during the 10-week training period. Health-related quality of life, reported as IBDQ total score, improved $19 \%$ in the intervention group and $8 \%$ in the control group. Scores for the IBDQ social sub-scale were significantly improved in the intervention group compared with controls $\left(\triangle \mathrm{IBDQ}_{\text {social }}=6.27 \pm 5.46\right.$ vs. $1.87 \pm 4.76, \mathrm{p}=$ 0.023). Conclusion: Patients suffering from moderately active IBD are capable of performing symptom-free regular endurance exercise. Our data support the assumption that PA is feasible in IBD patients. PA may furthermore improve quality of life through improvements in social well-being, and may, therefore, be a useful adjunct to IBD therapy.

(c) 2015 S. Karger AG, Basel

\section{Background}

Gastrointestinal as well as extra-intestinal discomfort negatively affects the quality of life in patients with Inflammatory Bowel Disease (Crohn's disease (CD) and ulcerative colitis (UC)) [1-3]. Besides somatic deterioration, the typical relapsing course of IBD often leads to
Dr. Peter Klare

II. Medizinische Klinik, Klinikum rechts der Isar Ismaninger Strasse 22 DE-81675 München (Germany)

E-Mail peter.klare@lrz.tum.de 
psychological distress, which evokes further impairment. Thus, patients suffering from IBD are frequently affected by depressive syndromes $[4,5]$. Despite multimodal medical treatments, including immune-modulatory drugs and antibodies, there are no cures for IBD. Drug therapy aims at altering the course of disease, reducing symptoms, and improving health-related quality of life (HRQOL) [6-9]. Therefore, strategies, including complementary pharmacological approaches and psychosocial support, are commonly used by patients with IBD [1013].

Regular physical activity (PA) has become an important complementary treatment strategy in several chronic diseases, including coronary heart disease, metabolic syndrome, heart failure, breast cancer, and depression [14-18]. However, PA as a therapeutic option for IBD has not been studied sufficiently, and little is known about the effect of regular PA on disease activity, inflammation, and quality of life [19]. As in other chronic diseases, muscle function peak power and peak oxygen uptake are reduced in IBD patients $[20,21]$. Furthermore, to date, no negative side effects of moderate exercise on the physical condition of IBD patients have been observed [22]. These data suggest that physical activity may be a safe method that benefits patients with IBD. Therefore, the purpose of this study is to compare the effects of a physical activity program on changes in HRQOL in IBD patients.

\section{Patients and Methods}

\section{Patients}

Patients were recruited during regular visits at the university hospital gastroenterology outpatient clinic between April and June 2013. In addition, patients were recruited during meetings of the German Crohn's Disease/ Ulcerative Colitis Association (Deutsche Morbus Crohn/Colitis ulcerosa Vereinigung, e.V.) selfhelp groups. Patients who were 18 years or older were eligible to participate if either CD or UC was diagnosed at least one year before screening. Patients in remission or with mild active disease (Crohn's Disease Activity Index (CDAI) $<220$ points or Rachmilewitz Index (RI) $<11$ points) were included. Exclusion criteria were high activity scores (CDAI $\geq 220$ or RI $\geq 11$ ) and/or contraindications to participation in regular PA (i.e., severe anemia, angina pectoris, severe ECG abnormalities). Patients with depression or psychosomatic disorders were not excluded. We furthermore excluded patients who participated in regular structured PA $(>2$ hours/week).

Explanatory material, including information about the study and possible health risks, was handed out. All participants gave written informed consent. The study was approved by the ethics committee of the Technical University of Munich (Protocol Number: 5709/13), and the trial is registered at clinicaltrials.gov study register (NCT01834573).
Assessment of HRQOL, IBD Activity, Physical Condition, and Medical History

All patients underwent physical examinations, 12-lead resting electrocardiography $(\mathrm{EKG})$, routine laboratory tests (including analyses for inflammation markers), and fecal calprotectin measurement before inclusion. Assessment of HRQOL was performed using the German version of the IBDQ. The IBDQ is a validated test consisting of 32 questions covering four quality of life dimensions (bowel, systemic, social and emotional) [23]. Questions can be responded to from 1 to 7 points, whereas higher values indicate better HRQOL. Groups of health-related quality of life were assessed directly before randomization and within 14 days after the end of the intervention or control period. Inflammatory bowel disease activity assessment was conducted using the CDAI or RI at the same time points. Both questionnaires assess subjective symptoms as well as objective measures (e.g., laboratory findings, body temperature). Scores $\leq 150$ and $\leq 4$ are regarded as disease remission in the CDAI and RI, respectively $[24,25]$. Values of $>220$ points have been used to define moderately active disease [26]. History of medication, alcohol, and tobacco use were assessed at the first visit before randomization (baseline values).

\section{Randomization}

Consecutive patients were block-randomized 1:1 to either intervention or control groups after verifying inclusion and exclusion criteria and receiving written informed consent. A computergenerated randomization list was used, and participants were stratified according to the two IBD entities (CD or UC). Block sizes varied between four and six patients.

\section{Intervention}

The exercise training was based on an established running program that was developed in Munich for untrained people [27]. The program is offered in three different forms depending on baseline Body Mass Index (BMI). Participants in the intervention group participated in the running program for $B M I \leq 25$. This consisted of supervised outdoor running at moderate intensity thrice per week for 10 weeks. Patients were advised to run or walk briskly in order to increase the heart ratio to the point of working up a sweat. 'Moderate intensity' was furthermore defined by the condition that participants were still able to talk while running. Patients randomized to the control group were encouraged to maintain their current lifestyle behaviors and to avoid PA exceeding two hours per week.

\section{Outcome Measures and Statistics}

The primary aim of the trial was a comparison of study groups regarding change in total HRQOL from baseline to ten weeks after treatment initiation. Changes in HRQOL subscales were defined as secondary endpoints. Further secondary outcome measures were within-group changes of IBDQ scales. Absolute IBDQ improvement of at least 27 points has been determined to correlate with a clinical improvement (CDAI score decrease of 100 points) in the short term [28]. We therefore chose an absolute IBDQ improvement of $\geq 27$ points as a secondary outcome measure. Finally, we performed within- and between-group comparisons of changes in IBD activity scores (CDAI, RI) as well as body weight and inflammation parameters (leucocyte counts, C-reactive protein, calprotectin in feces). 
Table 1. Baseline levels of patient characteristics, disease activity scores and HRQOL of 30 cases included

\begin{tabular}{|c|c|c|c|}
\hline Age, years & $41.1 \pm 14.1$ & $39.7 \pm 14.7$ & $42.5 \pm 13.9$ \\
\hline Gender, male, \% & $8(27)$ & $3(20)$ & $5(33)$ \\
\hline Disease duration, years & $13.0 \pm 8.8$ & $14.2 \pm 10.9$ & $11.7 \pm 6.2$ \\
\hline $\mathrm{CD} / \mathrm{UC}, \%$ & $19 / 11(63 / 37)$ & $10 / 5(67 / 33)$ & $9 / 6(60 / 40)$ \\
\hline \multicolumn{4}{|l|}{ Disease activity } \\
\hline Crohn's Disease Activity Index & $66.8 \pm 42.4$ & $68.8 \pm 44.1$ & $64.7 \pm 43.2$ \\
\hline Patients taking IBD specific drugs, \% & $26(87)$ & $12(80)$ & $14(93)$ \\
\hline \multicolumn{4}{|l|}{ IBD specific drugs, $\%$} \\
\hline Prednisolone (patients using P.) & $5(17)$ & $4(27)$ & $1(6)$ \\
\hline Budesonide (patients using B.) & $5(17)$ & $3(20)$ & $2(13)$ \\
\hline Mesalazine (patients using M.) & $8(27)$ & $3(20)$ & $5(33)$ \\
\hline Azathioprine/6-MP (patients using A./6MP) & $8(27)$ & $3(20)$ & $5(33)$ \\
\hline Weight, kg & $67.0 \pm 15.5$ & $61.0 \pm 9.7$ & $72.9 \pm 18.2$ \\
\hline Smoker, \% & $4(13)$ & $2(13)$ & $2(13)$ \\
\hline Alcohol consumption, $\%$ & $12(40)$ & $8(53)$ & $4(27)$ \\
\hline \multicolumn{4}{|l|}{ IBDQ values (baseline) } \\
\hline IBDQ total score & $162.1 \pm 33.0$ & $156.5 \pm 35.0$ & $167.7 \pm 31.1$ \\
\hline IBDQ emotional score & $57.7 \pm 15.0$ & $54.4 \pm 14.7$ & $61.0 \pm 15.1$ \\
\hline IBDQ bowel score & $54.4 \pm 8.7$ & $54.2 \pm 9.0$ & $54.6 \pm 8.8$ \\
\hline IBDQ social score & $27.4 \pm 7.7$ & $25.2 \pm 7.5$ & $29.7 \pm 7.5$ \\
\hline IBDQ systemic score & $22.6 \pm 6.1$ & $22.7 \pm 7.2$ & $22.4 \pm 5.0$ \\
\hline Hemoglobin, g/dl & $13.4 \pm 1.8$ & $13.0 \pm 1.7$ & $13.9 \pm 1.8$ \\
\hline Leucocyte count, g/l & $7.3 \pm 2.5$ & $7.0 \pm 2.2$ & $7.5 \pm 2.8$ \\
\hline $\mathrm{CRP}, \mathrm{mg} / \mathrm{dl}$ & $0.3(<0.1$ to 1.3$)$ & $0.2(<0.1$ to 1.3$)$ & $0.3(<0.1$ to 1.1$)$ \\
\hline
\end{tabular}

Numbers are mean \pm standard deviation, median (minimum-maximum), or frequencies (percentages).

Statistical Analysis

As the study was planned as a feasibility study, sample size was not calculated a priori. Statistical analyses were performed using SAS version 9.3 and $R$ version 3.3.1. A p value $<0.05$ was considered statistically significant.

Quantitative data at baseline and at the end of follow-up were described by mean and standard deviation, if data followed a normal distribution, or by median, minimum, and maximum (crp, calprotectin, CDAI, and RI score). As no relevant deviations from the normal distribution were detected for calculated changes from baseline to end of follow-up for all quantities, these changes are summarized by means and standard deviations. Consequently, mean differences between groups were compared using the twosample $t$ test, and within-group changes were assessed using paired t-tests. For relevant measures, $95 \%$ confidence intervals are presented.

Distributions of categorical data are presented by absolute frequencies and percentages. The proportion of patients with a clinically relevant increase in IBDQ of at least 27 points was compared between groups using Fisher's exact test.

Physical Exercise and Inflammatory

Bowel Disease

\section{Results}

\section{Subjects}

A total of 132 patients were screened for participation, and 36 (26 female) were included (table 1). There were three dropouts in the intervention group (two due to lack of motivation and one due to injury unrelated to the intervention) and three in the control group (two did not attend follow-up, and one had incomplete HRQOL data; fig. 1). All of the IG dropouts canceled participation before the beginning of the intervention. Therefore, complete data for per-protocol analysis was available in 30 cases (fig. 1).

Inflammatory Bowel Disease had been diagnosed on average $13.0 \pm 8.8$ years before study participation. No relevant differences were observed between groups with regard to patient characteristics, IBD-associated factors, or HRQOL at baseline (table 1). 
Fig. 1. Patient flow through the trial.

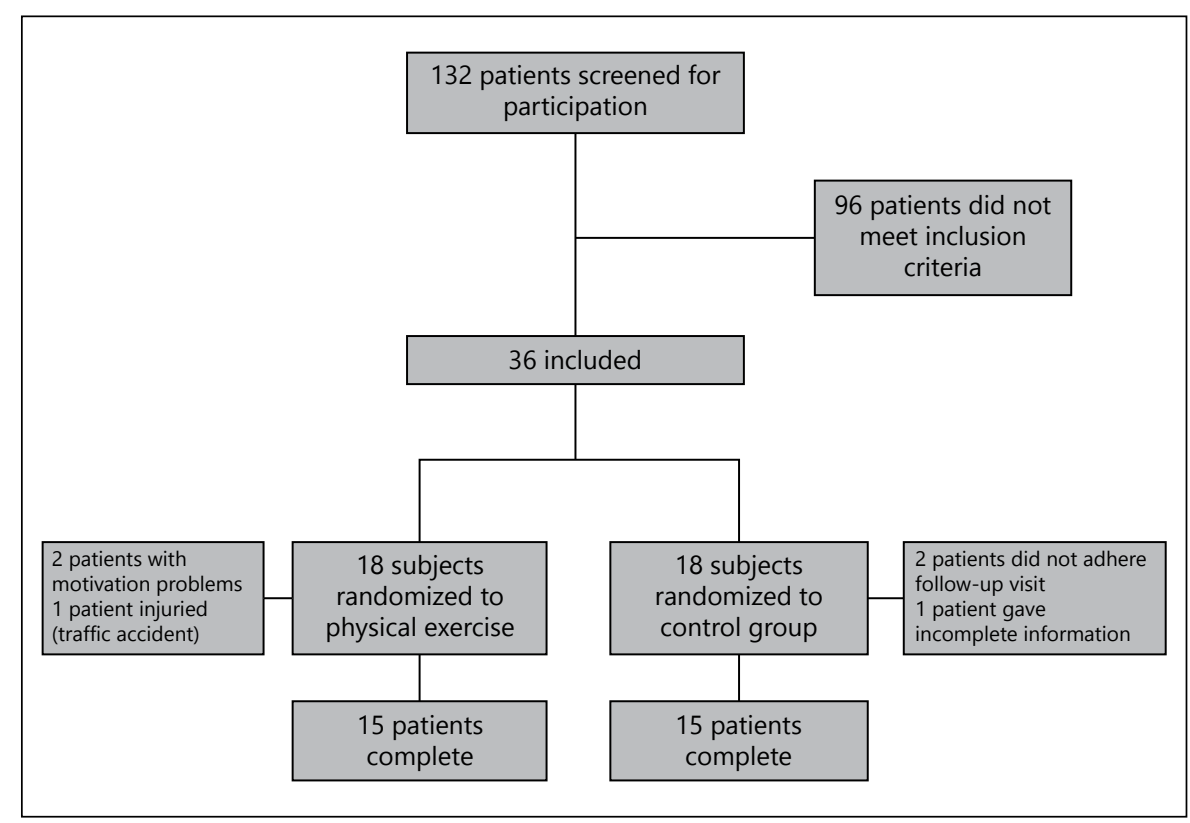

\section{Feasibility of Training and Adverse Events}

Fifteen patients completed the 10-week training program. Patients performed a mean of $24 \pm 4$ out of 30 possible sessions. Out of a total of 89 missed sessions, only one absence was caused by IBD complaints. Reasons for not attending were lack of time $(28 / 89,31 \%)$, joint discomfort not related to IBD $(14 / 89,16 \%)$, and other reasons not related to IBD (e.g., hot weather or rain, absences due to holidays, other commitments; $47 / 89,53 \%$ ). All patients rated training as a success (yes/no question). Fourteen out of 15 participants in the intervention group said they would participate in a comparable program again. No serious or training-related adverse events occurred during the intervention in IG or CG. Only one patient reported mild abdominal symptoms during and after training.

\section{Physical Activity in the Control Group}

No participants in the control group exceeded two hours per week of PA. Twelve of 15 participants (80\%) reported no PA at all, and three (20\%) indicated that they had participated in weekly sports activities. Of these three, one participated in singles tennis; one practiced yoga; and one surfed or played volleyball.

\section{Health-Related Quality of Life}

Improvements in total IBDQ score $\left(\triangle \mathrm{IBDQ}_{\text {total }}=\right.$ $28.3 \pm 24.5$ vs. $14.5 \pm 16.1, \mathrm{p}=0.081)$, bowel sub-score $\left(\triangle \mathrm{IBDQ}_{\text {bowel }}=6.8 \pm 7.5\right.$ vs. $\left.4.7 \pm 5.2, \mathrm{p}=0.376\right)$, and emo- tional $\left(\triangle \mathrm{IBDQ} \mathrm{Q}_{\text {emotional }}=11.1 \pm 10.7\right.$ vs. $4.8 \pm 7.1, \mathrm{p}=$ $0.068)$ and systemic sub-score $\left(\triangle \mathrm{IBDQ}_{\text {systemic }}=4.1 \pm 5.4\right.$ vs. $3.2 \pm 4.5, \mathrm{p}=0.611$ ) did not differ significantly between the intervention and the control group (table 2; fig. 2). Participants in the intervention group improved their social well-being to a greater extent than did participants in the control group $\left(\triangle \mathrm{IBDQ}_{\text {social }}=6.3 \pm 5.5\right.$ vs. $1.9 \pm 4.8$, $\mathrm{p}=0.026)$. Six patients $(40 \%)$ in the intervention group and one $(6.7 \%)$ in the control group $(\mathrm{p}=0.080)$ improved total IBDQ score by at least 27 points, which was the suggested threshold for clinical improvement.

\section{IBDQ Score Changes within Groups}

IBDQ total scores were improved in IG compared with baseline (study end vs. start: $184.9 \pm 20.9$ vs. $156.5 \pm 35.0$, $\mathrm{p}=0.001$ ). Statistically significant increases were also observed in all IBDQ dimensions, including emotional $(65.5 \pm 11.1$ vs. $54.4 \pm 14.7, \mathrm{p}=0.001)$, bowel $(61.0 \pm 5.2$ vs. $54.2 \pm 9.0, \mathrm{p}=0.004)$, social $(31.5 \pm 5.6$, vs. $25.2 \pm 7.5, \mathrm{p}=$ $0.001)$, and systemic $(26.9 \pm 3.1$ vs. $22.7 \pm 7.2, \mathrm{p}=0.010)$.

IBDQ total scores were also improved in controls compared to baseline values (study end vs. start: $182.2 \pm$ 26.6 vs. $167.7 \pm 31.1, \mathrm{p}=0.004)$. Statistically significant increases were observed for the emotional ( $65.8 \pm 14.6 \mathrm{vs}$. $61.0 \pm 15.1, \mathrm{p}=0.021)$, bowel $(59.3 \pm 7.1$ vs. $54.6 \pm 8.8, \mathrm{p}=$ $0.004)$, and systemic dimensions ( $25.6 \pm 5.3$ vs. $22.4 \pm 5.0$, $\mathrm{p}=0.016)$. However, the IBDQ social dimension score did not significantly improve in controls from baseline to follow-up $(29.7 \pm 7.5$ vs. $31.5 \pm 5.1, \mathrm{p}=0.151)$. 
Fig. 2. Comparison of intervention and control group regarding changes (followup - baseline values) in IBDQ scores (German Version). Lines indicate mean \pm standard deviation.

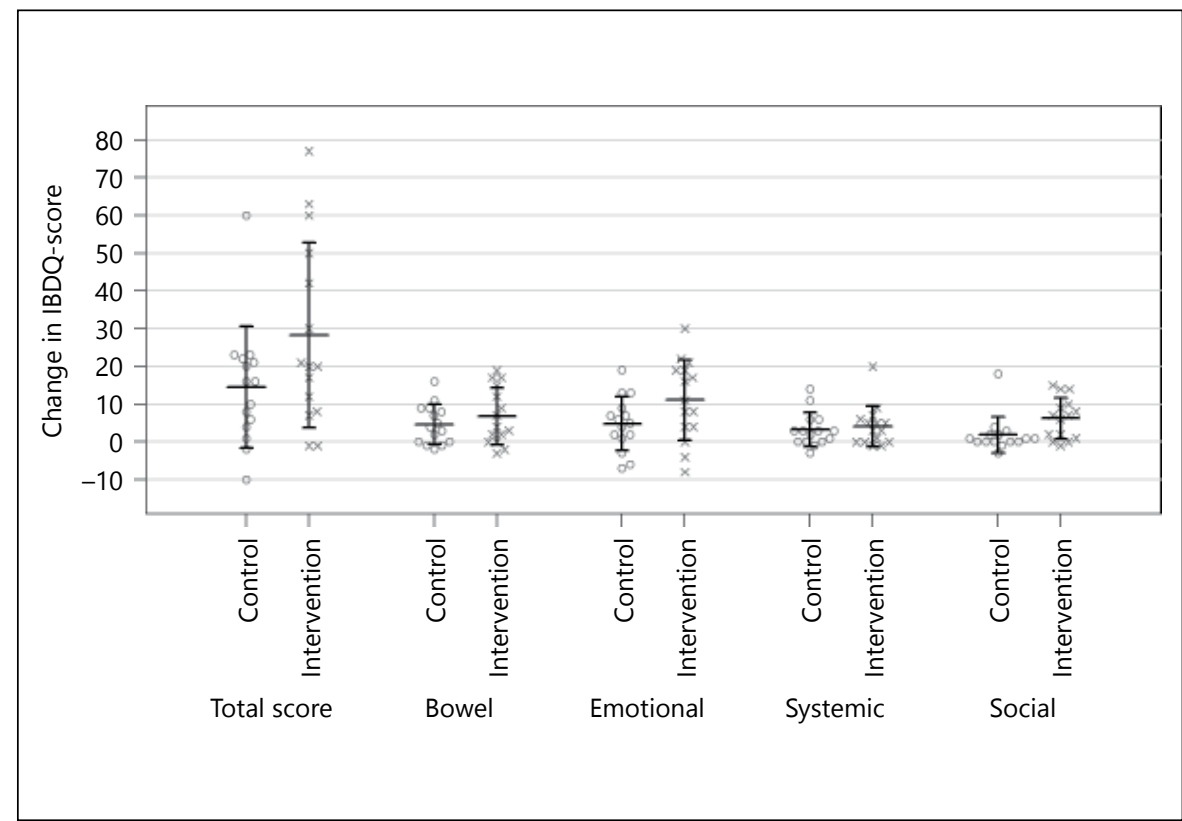

Table 2. Baseline and 10-week follow-up IBDQ scores in IG and CG ( $\mathrm{n}=30$ )

\begin{tabular}{|c|c|c|c|c|c|c|c|}
\hline Emotional & $\begin{array}{l}\mathrm{IG} \\
\mathrm{CG}\end{array}$ & $\begin{array}{l}54.4 \pm 14.7 \\
61.0 \pm 15.1\end{array}$ & $\begin{array}{l}65.5 \pm 11.1 \\
65.8 \pm 14.6\end{array}$ & $\begin{array}{c}11.1 \pm 10.7 \\
4.8 \pm 7.1\end{array}$ & $\begin{array}{l}0.001 \\
0.021\end{array}$ & $6.3(-0.5$ to 13.2$)$ & 0.068 \\
\hline Social & $\begin{array}{l}\mathrm{IG} \\
\mathrm{CG}\end{array}$ & $\begin{array}{l}25.2 \pm 7.5 \\
29.7 \pm 7.5\end{array}$ & $\begin{array}{l}31.5 \pm 5.6 \\
31.5 \pm 5.1\end{array}$ & $\begin{array}{l}6.3 \pm 5.5 \\
1.9 \pm 4.8\end{array}$ & $\begin{array}{l}0.001 \\
0.151\end{array}$ & $4.4(0.6$ to 8.2$)$ & $0.026^{*}$ \\
\hline Systemic & $\begin{array}{l}\mathrm{IG} \\
\mathrm{CG}\end{array}$ & $\begin{array}{l}22.7 \pm 7.2 \\
22.4 \pm 5.0\end{array}$ & $\begin{array}{l}26.9 \pm 3.1 \\
25.6 \pm 5.3\end{array}$ & $\begin{array}{l}4.1 \pm 5.4 \\
3.2 \pm 4.5\end{array}$ & $\begin{array}{l}0.010 \\
0.016\end{array}$ & $0.9(-2.8$ to 4.7$)$ & 0.611 \\
\hline
\end{tabular}

Numbers are mean \pm standard deviation.

\section{Disease Activity and Other Measurements}

Change of disease activity scores, laboratory results, and body composition did not differ significantly between groups (table 3). Regarding within-group comparison, leucocyte counts showed a statistically significant decrease in IG $(7.0 \pm 2.2$ vs. $5.6 \pm 1.5, p=0.016)$. We observed a change in calprotectin level in IG (mean increase of $185.0 \pm 324.8$ $\mathrm{mg} / \mathrm{kg}, \mathrm{p}=0.062$ ), but the increase was not significantly different from zero. Differences in CG were similarly distributed (mean increase of $210.3 \pm 621.3, p=0.245$ ). Inflammatory parameters, IBD disease activity scores, and body composition measures are given in table 3 . 
Table 3. Baseline and 10-week follow-up data: disease activity, body composition and laboratory results in IG and CG $(\mathrm{n}=30$ )

\begin{tabular}{|c|c|c|c|c|c|c|c|}
\hline Variable & $\begin{array}{l}\text { Group } \\
\text { asgmt }\end{array}$ & $\begin{array}{l}\text { Baseline } \\
\text { data }\end{array}$ & $\begin{array}{l}\text { Follow-up } \\
\text { data }\end{array}$ & $\begin{array}{l}\text { Within group } \\
\text { mean change } \\
\text { [follow-up - } \\
\text { baseline] }\end{array}$ & $\begin{array}{l}\text { Within- } \\
\text { group } \\
\text { p value }\end{array}$ & $\begin{array}{l}\text { Mean change } \\
\text { between groups } \\
\text { [IG-CG] } \\
(95 \% \mathrm{CI})\end{array}$ & $\begin{array}{l}\text { Between } \\
\text { groups } \\
\text { p value }\end{array}$ \\
\hline CDAI & $\begin{array}{l}\mathrm{IG} \\
\mathrm{CG}\end{array}$ & $\begin{array}{l}51(28 \text { to } 149) \\
67(0-144)\end{array}$ & $\begin{array}{l}41(19-141) \\
50(17-105)\end{array}$ & $\begin{array}{r}-11.3 \pm 38.0 \\
-7.6 \pm 30.0\end{array}$ & $\begin{array}{l}0.372 \\
0.471\end{array}$ & $-3.7(-36.8$ to 29.3$)$ & 0.814 \\
\hline Weight, kg & $\begin{array}{l}\mathrm{IG} \\
\mathrm{CG}\end{array}$ & $\begin{array}{l}61.0 \pm 9.7 \\
72.9 \pm 18.2\end{array}$ & $\begin{array}{l}62.0 \pm 9.0 \\
72.9 \pm 18.0\end{array}$ & $\begin{array}{r}1.0 \pm 1.9 \\
-0.1 \pm 1.7\end{array}$ & $\begin{array}{l}0.063 \\
0.882\end{array}$ & $1.0(-0.3$ to 2.4$)$ & 0.124 \\
\hline $\mathrm{BMI}, \mathrm{kg} / \mathrm{m}^{2}$ & $\begin{array}{l}\mathrm{IG} \\
\mathrm{CG}\end{array}$ & $\begin{array}{l}21.0 \pm 2.8 \\
24.6 \pm 4.5\end{array}$ & $\begin{array}{l}21.4 \pm 2.7 \\
24.6 \pm 4.3\end{array}$ & $\begin{array}{r}0.4 \pm 0.7 \\
-0.0 \pm 0.6\end{array}$ & $\begin{array}{l}0.054 \\
0.751\end{array}$ & $0.4(0.0$ to 0.9$)$ & 0.077 \\
\hline CRP, mg/dl & $\begin{array}{l}\mathrm{IG} \\
\mathrm{CG}\end{array}$ & $\begin{array}{l}0.2(<0.1-1.3) \\
0.3(<0.1-1.1)\end{array}$ & $\begin{array}{l}0.2(<0.1-0.9) \\
0.2(<0.1-1.4)\end{array}$ & $\begin{array}{r}-0.1 \pm 0.3 \\
0.0 \pm 0.4\end{array}$ & $\begin{array}{l}0.520 \\
0.736\end{array}$ & $0.0(-0.3$ to 0.2$)$ & 0.875 \\
\hline $\begin{array}{l}\text { Calprotectin, } \\
\mathrm{mg} / \mathrm{kg}\end{array}$ & $\begin{array}{l}\text { IG } \\
\text { CG }\end{array}$ & $\begin{array}{c}68.0(<30-227.0) \\
139.0(<0.1-545.0)\end{array}$ & $\begin{array}{l}141.0(<30-1,069.0) \\
229.0(59.0-1,832.0)\end{array}$ & $\begin{array}{l}185.0 \pm 324.8 \\
210.3 \pm 621.3\end{array}$ & $\begin{array}{l}0.062 \\
0.245\end{array}$ & $-25.3(-433.6$ to 383.0$)$ & 0.898 \\
\hline
\end{tabular}

Numbers are mean \pm standard deviation or median (minimum-maximum).

\section{Discussion}

\section{Impact of Physical Exercise on HRQOL}

We conducted a randomized controlled study in order to investigate the impact of 10 weeks of moderate intensity physical activity on social and emotional aspects of health-related quality of life (HRQOL) in patients with mild inflammatory bowel disease (IBD). In the PA group, a mean increase in the total IBDQ score that was 13.8 points higher than in the control group was observed. However, this difference was not statistically significant (95\% CI: 1.8 to $29.4 ; \mathrm{p}=0.081$ ). The mean change in the social well-being dimension of HRQOL was significantly higher for IG compared to CG.

Our study therefore suggests a beneficial effect of regular exercise on social well-being in IBD patients. However, these insights derive from secondary outcome measures in a study with a small sample size. Results must therefore be interpreted with caution. Until now, there are very few randomized controlled trials available on the effect of PA on HRQOL in patients with IBD. In one uncontrolled trial, Loudon et al. conducted a three-month walking program in 12 patients with mildly active Crohn's disease (CD). No adverse events were observed, and the patients improved HRQOL measured by total IBDQ scores [29]. $\mathrm{Ng}$ and colleagues also investigated the effect of a three-month low-intensity walking program (30 min of walking, thrice a week) in CD patients with moderate disease, and although improvements in HRQOL were observed, there were no differences between groups [30]. In another study, 16 patients suffering from ulcerative colitis (UC) participated in six hours per week of stress management training, moderate physical exercise, and behavioral techniques for a total of 10 weeks [31]. In comparison to controls, participants showed a greater improvement in only the IBDQ dimension related to bowel discomfort. However, compared with our study, this study was not focused on physical activity, and the participants had some influence on their allocation assignments.

The group-based PA applied in the current trial necessarily included the formation of interpersonal contacts. By contrast, controls continued their previous lifestyle likely having fewer opportunities for social interaction. This fact might have influenced the observed improve- 
ments of the social well-being component of HRQOL, as there is evidence in literature that social support is capable of influencing emotional IBDQ dimension scores in IBD [32]. Interestingly, both IG and CG improved total HRQOL, with no statistically significant between-group differences. Patients in CG reported less than 2 hours of PA per week during the time of the intervention. Unfortunately, we were not able to measure PA objectively (e.g. with accelerometers) and therefore do not know for sure how active they were. Other studies applying a similar design have observed large crossover effects, in that controls became more active due to their inclusion in a study investigating exercise [33]. Although crossover is likely to affect any study comparing the effects of exercise with non-exercise controls, further studies with larger samples and prescribed compensation for controls may help resolve some of these issues.

\section{Sports Are Feasible in IBD Patients Suffering from Moderately Active Disease}

The implementation of regular PA for patients with IBD has gained recent support. There is no evidence of negative side effects of moderate PA in stable IBD patients $[22,34,35]$. Furthermore, data suggest that especially extra-intestinal aspects of IBD (e.g. osteoporosis) are improved by PA [36]. Traditionally, it was speculated that in patients with IBD with reduced exercise tolerance, regular exercise may actually do more harm than benefit [19]. Currently, the performance of regular exercise is desirable in most patient populations, including patients with IBD, and these concerns seem to have been unwarranted [37]. In agreement with current beliefs, we observed that running exercise thrice a week for 10 weeks is feasible in IBD. No serious adverse events occurred during the trial, and only one patient reported mild abdominal symptoms. Furthermore, we observed no relevant difference in change of inflammation markers between groups. In the IG, leucocyte counts decreased. This result is contrary to a recent finding from Ploeger et al., who found that leucocyte counts in pediatric IBD patients rose after the conduction of a bicycle ergometer training [38]. In our trial follow-up, calprotectin concentration in IG was observed to be higher than at baseline, but the mean increase did not differ significantly from zero (185.0 \pm $324.8 \mathrm{mg} / \mathrm{kg}, \mathrm{p}=0.062$ ). This fact may still be an indication of increased inflammation.

It is currently unknown at which exercise volume and intensity IBD patients would benefit the most. In a mouse model of colitis, forced exercise resulted in an increased mortality rate, whereas voluntary training had a protective effect on inflammation and diarrhea [39]. Regarding the relationship between exercise and course of disease in humans, our results suggest that moderate PA is feasible in stable IBD patients with mild activity, which is in accordance with data collected from previous clinical trials [29$31,38,40]$. Randomized controlled trials with adequate statistical power may be able to build on the current trial and definitively illustrate the effects of different volumes and intensities of PA on HRQOL and symptoms in IBD.

\section{Conclusion}

Our data suggest that regular physical activity is a useful complementary therapy tool that is capable of improving HRQOL and social well-being in patients suffering from mild active IBD. Patients with IBD seem to be able to perform running and walking without experiencing clinically meaningful adverse effects on intestinal and general health.

\section{Limitations}

As no assumptions were made regarding the effect size, no sample size was calculated. Due to the small sample size, results must be interpreted with caution. Furthermore, in order to highlight the actual effect of PA, we conducted per-protocol analysis and included patients with complete information regarding the primary endpoint measures. This method may have increased the likelihood for false-positive findings. Furthermore, controls were not compensated, which might have led to bias. Finally, as we did not measure PA in controls objectively (e.g., with accelerometers), we do not know for sure how active they were. Crossover might have affected our results. Therefore, we are not able to explain why HRQOL improved also in controls.

\section{Disclosure Statement}

The authors declare that no conflict of interest exists with regard to the contents of this article.

\section{Author Contributions}

Peter Klare, Martin Halle, and Wolfgang Huber carried out the planning of the study, interpretation of the data, and preparation of the article. Johanna Nigg, Johannes Nold, and Peter Klare car- 
ried out the data acquisition and supervised the training sessions. Bernhard Haller was responsible for the statistical analysis and drafting of the article (Methods section). Anne B. Krug, Sebastian Mair, and Christoph K. Thoeringer participated in data acquisition. Jeff W. Christle and Roland M. Schmid participated in coordination and helped draft the article.

\section{Acknowledgment}

None.

\section{References}

1 Bernklev T, Jahnsen J, Lygren I, Henriksen M, Vatn M, Moum B: Health-related quality of life in patients with inflammatory bowel disease measured with the short form-36: psychometric assessments and a comparison with general population norms. Inflamm Bowel Dis 2005;11:909-918.

2 Romberg-Camps MJ, Bol Y, Dagnelie PC, Hesselink-van de Kruijs MA, Kester AD, Engels LG, van Deursen C, Hameeteman WH, Pierik M, Wolters F, Russel MG, Stockbrügger RW: Fatigue and health-related quality of life in inflammatory bowel disease: results from a population-based study in the Netherlands: the IBD-South Limburg cohort. Inflamm Bowel Dis 2010;16:2137-2147.

3 Kunz JH, Hommel KA, Greenley RN: Health-related quality of life of youth with inflammatory bowel disease: a comparison with published data using the PedsQL 4.0 generic core scales. Inflamm Bowel Dis 2010; 16:939-946.

4 Long MD, Kappelman MD, Martin CF, Chen W, Anton K, Sandler RS: Risk factors for depression in the elderly inflammatory bowel disease population. J Crohns Colitis 2014;8: 113-119.

5 Fuller-Thomson E, Sulman J: Depression and inflammatory bowel disease: findings from two nationally representative Canadian surveys. Inflamm Bowel Dis 2006;12:697-707.

6 Bandzar S, Gupta S, Platt MO: Crohn's disease: a review of treatment options and current research. Cell Immunol 2013;286:45-52.

7 Cohen LB, Nanau RM, Delzor F, Neuman MG: Biologic therapies in inflammatory bowel disease. Transl Res 2014;163:533-556.

8 Kornbluth A, Sachar DB; Practice Parameters Committee of the American College of Gastroenterology: Ulcerative colitis practice guidelines in adults: American College of Gastroenterology, Practice Parameters Committee. Am J Gastroenterol 2010;105:501523.

9 Lichtenstein GR, Hanauer SB, Sandborn WJ; Practice Parameters Committee of American College of Gastroenterology: Management of Crohn's disease in adults. Am J Gastroenterol 2009;104:465-483.

10 Hilsden RJ, Scott CM, Verhoef MJ: Complementary medicine use by patients with inflammatory bowel disease. Am J Gastroenterol 1998;93:697-701.

11 Joos S, Rosemann T, Szecsenyi J, Hahn EG, Willich SN, Brinkhaus B: Use of complemen- tary and alternative medicine in Germany - a survey of patients with inflammatory bowel disease. BMC Complement Altern Med 2006; 6:19.

12 Langhorst J, Anthonisen IB, Steder-Neukamm U, Lüdtke R, Spahn G, Michalsen A, Dobos GJ: Amount of systemic steroid medication is a strong predictor for the use of complementary and alternative medicine in patients with inflammatory bowel disease: results from a German national survey. Inflamm Bowel Dis 2005;11:287-295.

13 Langhorst J, Anthonisen IB, Steder-Neukamm U, Luedtke R, Spahn G, Michalsen A, Dobos GJ: Patterns of complementary and alternative medicine (CAM) use in patients with inflammatory bowel disease: perceived stress is a potential indicator for CAM use. Complement Ther Med 2007;15: 30-37.

14 Zou LY, Yang L, He XL, Sun M, Xu JJ: Effects of aerobic exercise on cancer-related fatigue in breast cancer patients receiving chemotherapy: a meta-analysis. Tumour Biol 2014; 35:5659-5667.

15 Courneya KS, Segal RJ, Mackey JR, Gelmon K, Friedenreich CM, Yasui Y, Reid RD, Jespersen D, Cook D, Proulx C, Trinh L, Dolan LB, Wooding E, Forbes CC, McKenzie DC: Effects of exercise dose and type on sleep quality in breast cancer patients receiving chemotherapy: a multicenter randomized trial. Breast Cancer Res Treat 2014;144:361369.

16 Piña IL, Apstein CS, Balady GJ, Belardinelli R, Chaitman BR, Duscha BD, Fletcher BJ, Fleg JL, Myers JN, Sullivan MJ; American Heart Association Committee on exercise, rehabilitation, and prevention: Exercise and heart failure: a statement from the American Heart Association Committee on exercise, rehabilitation, and prevention. Circulation 2003;107: 1210-1225.

17 Edelmann F, Gelbrich G, Düngen HD, Fröhling S, Wachter R, Stahrenberg R, Binder L, Töpper A, Lashki DJ, Schwarz S, HerrmannLingen C, Löffler M, Hasenfuss G, Halle M, Pieske B: Exercise training improves exercise capacity and diastolic function in patients with heart failure with preserved ejection fraction: results of the Ex-DHF (Exercise training in Diastolic Heart Failure) pilot study. J Am Coll Cardiol 2011;58:1780-1791.

18 Cooney GM, Dwan K, Greig CA, Lawlor DA, Rimer J, Waugh FR, McMurdo M, Mead GE:
Exercise for depression. Cochrane Database Syst Rev 2013;9:CD004366.

19 Pérez CA: Prescription of physical exercise in Crohn's disease. J Crohns Colitis 2009;3:225231.

20 Wiroth JB, Filippi J, Schneider SM, Al-Jaouni $\mathrm{R}$, Horvais N, Gavarry O, Bermon S, Hébuterne $\mathrm{X}$ : Muscle performance in patients with Crohn's disease in clinical remission. Inflamm Bowel Dis 2005;11:296-303.

21 Ploeger HE, Takken T, Wilk B, Issenman RM, Sears R, Suri S, Timmons BW: Exercise capacity in pediatric patients with inflammatory bowel disease. J Pediatr 2011;158:814-819.

22 Bilski J, Brzozowski B, Mazur-Bialy A, Sliwowski Z, Brzozowski T: The role of physical exercise in inflammatory bowel disease. Biomed Res Int 2014;2014:429031.

23 Häuser W, Dietz N, Grandt D, Steder-Neukamm U, Janke KH, Stein U, Stallmach A: Validation of the inflammatory bowel disease questionnaire IBDQ-D, German version, for patients with ileal pouch anal anastomosis for ulcerative colitis. Z Gastroenterol 2004;42: 131-139.

24 Best WR, Becktel JM, Singleton JW, Kern F Jr: Development of a Crohn's disease activity index. National Cooperative Crohn's Disease Study. Gastroenterology 1976;70:439-444.

25 Rachmilewitz D: Coated mesalazine (5-aminosalicylic acid) versus sulphasalazine in the treatment of active ulcerative colitis: a randomised trial. BMJ 1989;298:82-86.

26 Hoffmann JC, Preiss JC, Autschbach F, Buhr HJ, Häuser W, Herrlinger K, Höhne W, Koletzko S, Krieglstein CF, Kruis W, Matthes H, Moser G, Reinshagen M, Rogler G, Schreiber S, Schreyer AG, Sido B, Siegmund B, Stallmach A, Bokemeyer B, Stange EF, Zeitz M: [Clinical practice guideline on diagnosis and treatment of Crohn's disease]. Z Gastroenterol 2008;46:1094-1146.

27 Halle M: Schritt für Schritt endlich fit: Das 10-Wochen-Programm. Munich, Wilhelm Goldmann Verlag, 2014.

28 Hlavaty T, Persoons P, Vermeire S, Ferrante M, Pierik M, Van Assche G, Rutgeerts P: Evaluation of short-term responsiveness and cutoff values of inflammatory bowel disease questionnaire in Crohn's disease. Inflamm Bowel Dis 2006;12:199-204.

29 Loudon CP, Corroll V, Butcher J, Rawsthorne $\mathrm{P}$, Bernstein $\mathrm{CN}$ : The effects of physical exercise on patients with Crohn's disease. Am J Gastroenterol 1999;94:697-703. 
$30 \mathrm{Ng} \mathrm{V}$, Millard W, Lebrun C, Howard J: Lowintensity exercise improves quality of life in patients with Crohn's disease. Clin J Sport Med 2007;17:384-388.

31 Elsenbruch S, Langhorst J, Popkirowa K, Müller T, Luedtke R, Franken U, Paul A, Spahn G, Michalsen A, Janssen OE, Schedlowski M, Dobos GJ: Effects of mind-body therapy on quality of life and neuroendocrine and cellular immune functions in patients with ulcerative colitis. Psychother Psychosom 2005;74:277-287.

32 Oliveira S, Zaltman C, Elia C, Vargens R, Leal A, Barros R, Fogaça H: Quality-of-life measurement in patients with inflammatory bowel disease receiving social support. Inflamm Bowel Dis 2007;13:470-474.

33 O'Connor CM, Whellan DJ, Lee KL, Keteyian SJ, Cooper LS, Ellis SJ, Leifer ES, Kraus WE, Kitzman DW, Blumenthal JA, Rendall DS,
Miller NH, Fleg JL, Schulman KA, McKelvie RS, Zannad F, Piña IL; HF-ACTION Investigators: Efficacy and safety of exercise training in patients with chronic heart failure: HFACTION randomized controlled trial. JAMA 2009;301:1439-1450.

34 Narula N, Fedorak RN: Exercise and inflammatory bowel disease. Can J Gastroenterol 2008;22:497-504.

35 Cosnes J: Smoking, physical activity, nutrition and lifestyle: environmental factors and their impact on IBD. Dig Dis 2010;28:411-417.

36 Robinson RJ, Krzywicki T, Almond L, al-Azzawi F, Abrams K, Iqbal SJ, Mayberry JF: Effect of a low-impact exercise program on bone mineral density in Crohn's disease: a randomized controlled trial. Gastroenterology 1998; 115:36-41.

37 Packer N, Hoffman-Goetz L, Ward G: Does physical activity affect quality of life, disease symptoms and immune measures in patients with inflammatory bowel disease? A systematic review. J Sports Med Phys Fitness 2010; 50:1-18.

38 Ploeger H, Obeid J, Nguyen T, Takken T, Issenman R, de Greef M, Timmons B: Exercise and inflammation in pediatric Crohn's disease. Int J Sports Med 2012;33:671-679.

39 Cook MD, Martin SA, Williams C, Whitlock K, Wallig MA, Pence BD, Woods JA: Forced treadmill exercise training exacerbates inflammation and causes mortality while voluntary wheel training is protective in a mouse model of colitis. Brain Behav Immun 2013;33: 46-56.

40 D'Incà R, Varnier M, Mestriner C, Martines D, D'Odorico A, Sturniolo GC: Effect of moderate exercise on Crohn's disease patients in remission. Ital J Gastroenterol Hepatol 1999; 31:205-210. 